\title{
In-class hierarchical team model as a no-cost strategy to improve student success: Integrated peer leadership program
}

\author{
Eliza J. Morris $\odot,{ }^{1, *}$ Mikkel Herholdt Jensen $\odot,{ }^{1}$ and Sayonita Ghosh Hajra ${ }^{2}$ \\ ${ }^{1}$ Department of Physics \& Astronomy, California State University, Sacramento, California 95819, USA \\ ${ }^{2}$ Department of Mathematics \& Statistics, California State University, Sacramento, California 95819, USA
}

(Received 17 December 2020; accepted 19 July 2021; published 30 August 2021)

\begin{abstract}
This work describes the implementation of a hierarchical team model, the Integrated Peer Leadership Program (IPLP), in a calculus-based college introductory physics classroom. Using this model, in which students in the course engage with their peers throughout the semester, we observe a significant increase in the students' likelihood of successfully completing the course. The model also reduces the gap between underrepresented minority (URM) and non-URM students. Learning gains using the IPLP format are improved as compared to previous data for traditional classes. The model transforms a traditional lecture style class into a student-centered class without additional time requirement or cost to the instructor or institution, and we anticipate that it will be portable to other large section introductory college science courses.
\end{abstract}

DOI: 10.1103/PhysRevPhysEducRes.17.023104

\section{INTRODUCTION}

Introductory college courses in science, technology, engineering, and mathematics (STEM) often pose a significant hurdle to college students. In a 2011 review of 11 studies, Freeman et al. found that about one out of every three college students failed such STEM courses [1]. Not passing these introductory STEM courses are roadblocks to student success [2]. Students early in their career are especially vulnerable to suffering from the emotional toll of failing, leading to delays in graduation, leaving STEM, or even leaving college altogether [3-5].

Several strategies have been found to help mitigate the high failure rate and improve learning outcomes in introductory college STEM classes. Courses with a highly structured course design result in significantly lower rates of failure [1] and active learning strategies, such as peer instruction [6], studio-style classes [7], and cooperative group learning [8], have been shown to improve student learning and retention in STEM programs [9-13]. Funded models incorporating a structure of paid, trained peer leaders across several STEM courses [14], or paid and trained undergraduate learning assistants [15-17] have also been successful in improving student success. However, there are challenges in the adoption of active learning and

*eliza.morris@csus.edu

Published by the American Physical Society under the terms of the Creative Commons Attribution 4.0 International license. Further distribution of this work must maintain attribution to the author(s) and the published article's title, journal citation, and DOI. peer-led instruction. Active learning instruction is often associated with smaller class sizes that create the need for more faculty and appropriate learning spaces [18,19]. Additionally, existing paid peer instruction models for large classes cost approximately $\$ 10000 /$ semester per course section, and procuring funding is recognized as a key challenge in the implementation of peer-led instruction $[19,20]$.

Here, we describe a structured peer leadership model, the Integrated Peer Leadership Program (IPLP), as a successful way of implementing active learning instruction in large classrooms with no additional financial or personnel requirements.

\section{COURSE DESIGN}

The IPLP model is developed and implemented in an introductory mechanics physics course. The course consists of 4 areas: motion, forces, conservation principles, and applications. Prior to the IPLP implementation, the course was taught with students attending one lecture section (approximately 80 students per section), and a different lab section (approximately 27 students per section). Lab and lecture sections had different student cohorts, different instructors, and a cursory level of coordination of the material covered in lab and lecture. In a typical active learning setting, students work in teams facilitated by paid teaching or learning assistants. The IPLP model also utilizes student teams, but instead students currently taking the class serve as peer leaders (see Sec. II C) and support their classmates in discussions and problem solving. This responsibility is rotated to different students each week. 


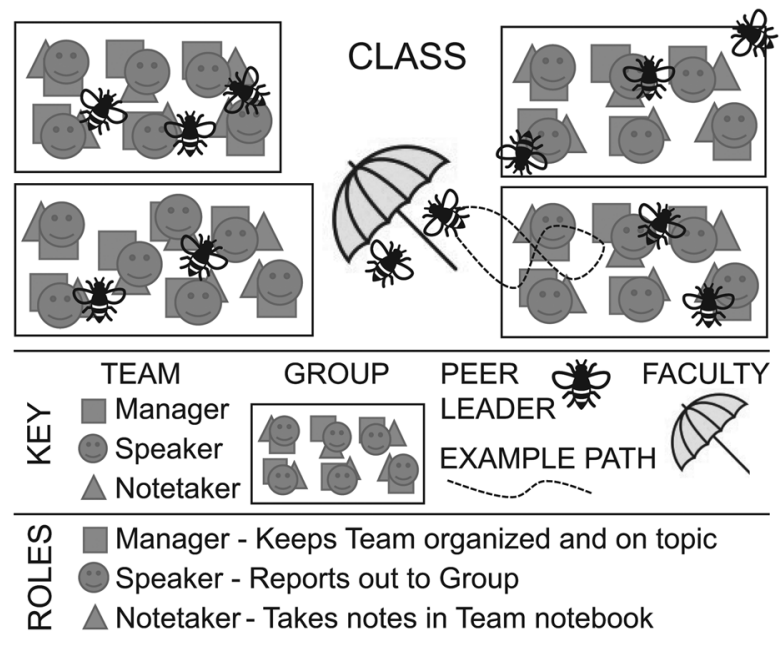

FIG. 1. Example classroom layout showing individual Teams of 3 students each, Groups of 6-7 Teams, the Peer Leaders, and the faculty. Peer Leaders travel between the Teams throughout their Group, returning to the instructor for additional assistance as needed; an example path is shown.

\section{A. Class time distribution and activities in a typical week}

The large lecture meets Monday, Wednesday, and Friday. Monday consists of an interactive lecture, where the instructor gives an overview lecture of the week's material, and students discuss lecture material with their teams and answer quick check questions. Wednesday includes a quiz combined with in-depth discussions of selected quiz questions. Friday is a problem-solving day, where teams work through a set of problems. A detailed breakdown of the week is illustrated in Supplemental Material, Sec. D [21]. In addition to these large class meetings, each student attends one of three 3hour lab sections, which are held in between the Wednesday and Friday lecture sections. During these lab times, students continue to engage with the same material in an exploratory, experimental setting.

\section{B. Hierarchical team structure}

A number of aspects of the course structure focus on team cooperation and peer accountability. Students are grouped by the instructor (see Sec. II D) into 27 small clusters of 3 students, called Teams, and 4 larger clusters consisting of 6-7 Teams each, called Groups. Each student is thus a member of both a Team and a Group. In addition to these student clusters are the Peer Leaders (see Sec. II C). In this article, we will refer to these Teams, Groups, and Peer Leaders capitalized as proper nouns, whereas general use of the word team, such as in team formation surveys, will remain lowercase. Every student serves as a Peer Leader for one textbook chapter during the semester. The Peer Leaders work with their peers at the Group level. There are 2-3 Peer Leaders for each Group. The role of the Peer Leader is described in detail in the next section. The hierarchical team structure is shown in Fig. 1.

\section{Peer leaders}

At the start of the semester, 6-7 Peer Leaders are randomly appointed by the instructor for every textbook chapter. Students serve as Peer Leaders for one week and no two members from the same Team serve as Peer Leaders on a similar topic. This helps ensure Teams have expertise from each course area.

Peer Leaders continue to participate in the class as normal, attending Monday lecture and completing Wednesday's quiz (see Sec. II E). In addition to completing the standard work, Peer Leaders support the class by moderating the Wednesday quiz Group discussions, presenting a summary of that discussion to the class, assisting Teams with problem solving on Friday, and replying to posts on the discussion forum throughout the week. A detailed breakdown of all Peer Leaders tasks, and where points are awarded, is included in Table III in Supplemental Material, Sec. D [21].

By spending time on additional preparation, and with the support of the instructor, the Peer Leaders are able to be valuable helpers in the classroom. The weekend before serving as Peer Leader, the student begins reading ahead and reviewing the week's assignments. On Monday, they attend an additional Peer Leader meeting with the instructor, where they review additional problems and ask questions from both reading and lecture.

Peer Leaders are instructed to answer questions when they can, consult each other if unsure, and always ask the instructor for help when necessary. Points are awarded to Peer Leaders for being helpful, not for being right. The network of Peer Leaders works together, with the instructor, to ensure that students are provided with the necessary assistance to ultimately arrive at the correct answers.

Because the Peer Leaders are fielding questions from the class, and the instructor is engaging primarily with the chapter's Peer Leaders, the total number of questions to the instructor, either in the discussions or through email, is comparable to non-IPLP classes. Additionally, group activities are enhanced with the presence of so many additional peer assistants. A more thorough breakdown of the instructor's time commitment, which is not increased from non-IPLP classes, is included in Table IV in Supplemental Material, Sec. D [21].

\section{Team building process}

Teams are formed based on student responses to a team formation survey (see Supplemental Material, Sec. A [21]) and performance on an in-class worksheet (see Supplemental Material, Sec. B [21]) given during the first week of the semester. The survey, based on a survey previously used in our institution's Physics department [16], helps identify student personalities, attitudes towards 
the course, and strengths. In grouping students, we focus on ensuring

that Teams have a wide range of preparatory knowledge and engagement styles. For example, multiple students self-identifying as always leading or planning to spend very little time on the course are not placed on the same Team. The worksheet is used as a secondary check on the Teams to make sure that no Team has more than one student scoring in the top $10 \%$ or bottom $10 \%$ on this worksheet.

Throughout the semester, team cohesion is promoted and maintained by developing a social contract (Supplemental Material, Sec. C [21]), maintaining the same Teams across all 6 hours of activities throughout the week, and by continued emphasis and encouragement from the instructor about the importance of collaboration over competition.

\section{E. Classroom discussions and problem-solving activities}

In conjunction with the Peer Leader mentoring, the class utilizes a structured discussion format, which focuses on questions selected by the instructor based on class performance on that week's quiz, which includes conceptual multiple-choice questions or quick worked questions designed to take about 2 min per question. An example question can be found in Supplemental Material, Sec. E [21]. These are completed and graded twice, once individually and again as a Team. The discussion format, summarized in Fig. 2, consists of four rounds: (1) an individual round, (2) a Team round, (3) a Group round, and (4) a class round. Typically, rounds 1 and 2 are completed as part of the quiz itself, with grades being assigned to all students. In rounds 3 and 4 , grades are assigned only to Peer Leaders. During the individual round (1), students are given time to individually reflect on the questions and asked to note their thoughts and ideas. In the Team round (2), the three Team members each select a role as manager, notetaker, or speaker. These roles often persist throughout the semester, but can change as the team dynamics change. The three Team members then share their ideas from their individual reflections. During the Team round, the manager works to ensure the Team stays on task. The notetaker writes down a summary of the Team's discussion in a Team notebook. The speaker presents a summary of the Team's discussion in the next round. In the Group round (3) the Peer Leaders take turns moderating the discussions while each Team's speaker reports their Team's thoughts on the question, including misconceptions that arose and any agreed upon solution. For each question covered within the Group, one of the Peer Leaders moderates the discussion as they work to assess the Group's agreement. For example, if many Teams report having similar discussions, the Peer Leader in charge of that question may step in to ask specifically for input from Teams with differing perspectives. These different perspectives from the Teams are summarized in a final report created by the Peer Leader in

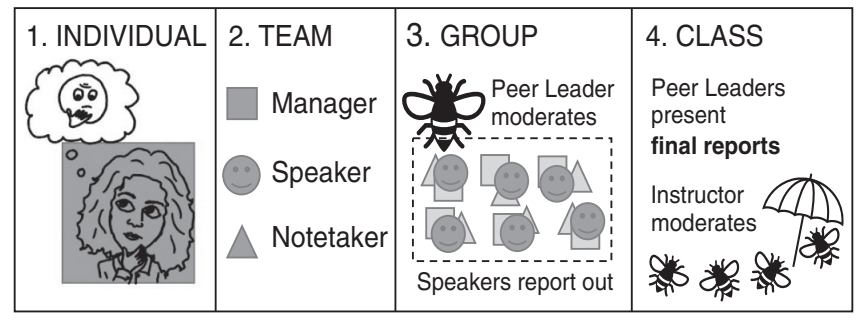

FIG. 2. The four rounds of the class discussion format. Grades are assigned for rounds 1 and 2 to the class, and for rounds 3 and 4 to Peer Leaders.

charge of that question. In the final class round (4), the instructor moderates as the Peer Leaders report their summaries focusing on the similarities and differences in problem-solving strategies between the different Teams, common misconceptions that popped up, and, finally, the agreed-upon solution to the question. After class, the Peer Leaders finalize their final report documents for their specific question, which are turned in for credit at the end of the week and made available to all students as an additional study resource.

This process allows for a multitiered engagement of students in which student discussions at the Team and Group level brings forward different viewpoints, problemsolving strategies, and misconceptions or misunderstandings, which then carry through to a discussion at the class level. After the class round, students continue the discussion in an online class discussion board, which is moderated by the Peer Leaders.

In addition to the Wednesday class discussions, on Fridays the class engages in a problem-solving session assisted by the Peer Leaders, who have already received feedback on that week's set of problems. As the Teams work through the material, the Peer Leaders circulate through their Group, providing encouragement and answering questions as able, always reaching out to the instructor when uncertain. The most important element of problemsolving days is that "I don't know" is an excellent response and an opportunity for everyone to learn, since the instructor is there to answer questions, as necessary.

\section{F. Technical details of implementation}

This course structure relies heavily on technological assistance. The individual and Team rounds of the Wednesday quizzes are run in an online quizzing platform, which allows for the immediate targeted selection of quiz questions to focus on in the Group round, based on class performance. The Team notebooks, completed by the Team notetaker, and the final reports, completed by the chapter Peer Leaders, are both done in collaboration documents within an online learning management system. Additionally, the Friday problem sets are submitted online, allowing the instructor early access to the Peer Leader's completed assignments. 


\section{METHODS}

This study was conducted at California State University, Sacramento (Sac State), a public 4-year university in California, USA, and was approved by the university's Institutional Review Board. Sac State is a 4-year minoritymajority institution, designated as both a Hispanic Serving Institution and an Asian American, Native American, Pacific Islander Serving Institution. $40 \%$ of students are underrepresented minorities, and $34 \%$ of students identify as first generation [22]. The IPLP format was offered for 4 semesters in the calculus-based introductory physics mechanics course (Physics 11A). Since 2011, the fraction of URM students (students identifying as Pacific Islander, Hispanic, or African American) in Physics 11A has averaged 32\% across all class sections, with no significant changes over the years [22]. The IPLP model was implemented by two different faculty and offered in one lecture section, partnered with three laboratory sections, each semester. Both faculty have taught non-IPLP sections with similar course materials, teaching methodology, and grading formats. The IPLP sections are offered without any learning or teaching assistants. In total, 319 students participated in the study.

To quantify the impact of our class structure on student success, we collected data on student course grades for selfreported URM and non-URM students. In addition, we quantify student learning gains using the Force Concept Inventory (FCI), a standard assessment commonly used in introductory physics mechanics classes [23]. Learning gains are calculated as normalized gains [24].

TABLE I. Student FCI and student DFW rates for sections implementing the IPLP model: Fall 2018 (35 URM, 45 non-URM students), Spring 2019 (30 URM, 50 non-URM students), Fall 2019 (33 URM, 49 non-URM), Spring 2020 (34 URM, 43 nonURM). The specific faculty member is indicated as Faculty A or B.

\begin{tabular}{lccrc}
\hline \hline & & & \multicolumn{2}{c}{ DFW } \\
\cline { 3 - 5 } & Faculty & FCI gain & URM & non-URM \\
\hline Fall 2018 & $\mathrm{A}$ & $35 \%$ & $3 \%$ & $7 \%$ \\
Spring 2019 & $\mathrm{B}$ & $38 \%$ & $13 \%$ & $2 \%$ \\
Fall 2019 & $\mathrm{A}$ & $29 \%$ & $3 \%$ & $6 \%$ \\
Spring 2020 & $\mathrm{A}$ & $44 \%$ & $15 \%$ & $12 \%$ \\
\hline \hline
\end{tabular}

\section{RESULTS AND DISCUSSION}

The IPLP model is structured around student teams and teamwork to implement both in-class active learning and a network of peer support and accountability among the students. By taking on a leadership role in the classroom for one week during the semester, students engage with the material on a deeper level, as they help others to master that week's material. The integrated lab and lecture sections are taught either by the same instructor or by a team of instructors working in close collaboration. This consistency across sections adds additional structure to the course from the student perspective and sets the expectation that all work is done in collaboration with the students' Team.

From 2011 to 2018 (prior to the launch of the IPLP) Physics $11 \mathrm{~A}$ had an average DFW rate among URM students of $29 \pm 4 \%$, as measured by the fraction of $\mathrm{D}$, $\mathrm{F}$, or W letter grades (DFW grades). The average DFW rate for non-URM students was $18 \pm 4 \%$. FCI and DFW data using the IPLP format are summarized in Table I.

We observe a marked improvement both in student learning outcomes, as measured using the FCI, and in student retention and completion rates when implementing the IPLP model (Table I). During the four semesters over which the program was implemented, class-wide FCI gains ranged from $29 \%$ to $44 \%$, with an average of $37 \pm 6 \%$, higher than the $23 \pm 4 \%$ reported by Hake in 1998 for 14 introductory physics courses taught using a traditional class format [24], and the 13\% gains on the Force and Motion Conceptual Evaluation (FMCE) [25] measured more recently across two lecture format classes at our institution [16]. As summarized in Table II, the average DFW rate using the IPLP model is significantly reduced as compared to both historical rates from 2011 to 2018, as well as traditionally taught Physics 11A sections offered since the introduction of the IPLP, from 2018 to 2020 . The average DFW rates for URM and non-URM students for the same instructor (Faculty A in Table I) in both the non-IPLP and the IPLP formats are also compared and show the same trend, although the number of semesters is too small to show statistical significance at the level of 0.05 . The grading breakdown for non-IPLP and the IPLP formats is nearly identical for Faculty A and typical for this course. A breakdown of all grading structures used is detailed in

TABLE II. Average DFW rates for the 2018-2020 IPLP classes, and classes not using the IPLP format. Uncertainty intervals indicate standard deviations over $N=14$ semesters for 2011-2018 (910 URM, 1954 non-URM students) and $N=4$ semesters for 2018-2020 (165 URM, 438 non-URM students). Faculty A data includes $N=3$ sections of IPLP (102 URM, 137 non-URM students) and $N=4$ sections of non-IPLP (129 URM, 215 non-URM students). Statistical $p$-values are based on comparison to the IPLP data (comparing "All" and "Faculty A" separately) and are calculated based on 2-tailed $t$ tests.

\begin{tabular}{|c|c|c|c|c|c|}
\hline & \multicolumn{2}{|c|}{ IPLP } & \multicolumn{3}{|c|}{ Non-IPLP } \\
\hline & All & Faculty A & Faculty A & All, 2011-2018 & All, 2018-2020 \\
\hline$U R M$ & $8 \pm 6 \%$ & $7 \pm 7 \%$ & $22 \pm 9 \%(p=0.063)$ & $29 \pm 4 \%(p<0.001)$ & $26 \pm 11 \%(p=0.037)$ \\
\hline Non-URM & $7 \pm 4 \%$ & $8 \pm 3 \%$ & $11 \pm 3 \%(p=0.22)$ & $18 \pm 4 \%(p<0.001)$ & $18 \pm 5 \%(p=0.010)$ \\
\hline
\end{tabular}


Supplemental Material, Sec. F [21]. Similar to what was noted previously by others [26,27], our institution's 20112018 data indicate that as exam weighting decreases, or participation weighting increases, the DFW gap between URM and non-URM increases. Interestingly, despite the relatively high quiz and participation grade weighting in the IPLP program, we do not observe a similar gap for this program.

In summary, over four semesters of implementing the IPLP model in our introductory physics classroom, we observe a significant decrease in DFW rates as compared both to historical data for the same course and to course offerings during the same semesters not using the IPLP format. The model also effectively eliminates the gap between URM and non-URM students. The only change necessary at an administrative level to implement the IPLP is to link enrollment between the lecture section and laboratory sections to make it possible to maintain the same instructor and student Teams across all sections. The structure does not impose an extra time commitment on the instructor's part, but rather a shift in how the instructor spends their time throughout each week, as summarized in Supplemental Material, Sec. D [21].

Notably, these outcomes are achieved within a large lecture class setting with no additional instructional or financial resources. This makes the model highly portable, and we anticipate that the IPLP can be implemented in other large introductory college science classes.

\section{ACKNOWLEDGMENTS}

We thank Dr. Kelly McDonald, Dr. Lynn Tashiro, and Dr. Vera Margoniner for comments and feedback during the writing process of this work. We gratefully acknowledge the anonymous peer reviewers whose insights and suggestions greatly improved this paper. This work was supported by a Sac State Pedagogy Enhancement Award from the Center for Teaching and Learning to E. J. M., M. H. J., and S. G. H., and by a California State University Assigned Time for Exceptional Levels of Service to Students Award to E. J. M.
[1] S. Freeman, D. Haak, and M. P. Wenderoth, Increased course structure improves performance in introductory biology, CBE Life Sci. Educ. 10, 175 (2011).

[2] S. M. Wischusen and E. W. Wischusen, Biology intensive orientation for students (BIOS): A biology "boot camp", CBE Life Sci. Educ. 6, 172 (2007).

[3] K. I. Maton, F. A. Hrabowski, III, and C. L. Schmitt, African American college students excelling in the sciences: College and postcollege outcomes in the Meyerhoff Scholars Program, J. Res. Sci. Teach. 37, 629 (2000).

[4] J. Becvar, G. Saupe, J. Noveron, and M. Narayan, Plus two peer-led team learning for large introductory STEM classes: Improved study skills, increased retention, and higher graduation rates, Front. Educ. Conf 1, T4D-15T4D-18 (2008).

[5] D. C. Haak, J. HilleRisLambers, E. Pitre, and S. Freeman, Increased structure and active learning reduce the achievement gap in introductory biology, Science 332, 1213 (2011).

[6] C. H. Crouch and E. Mazur, Peer Instruction: Ten years of experience and results, Am. J. Phys. 69, 970 (2001).

[7] R. J. Beichner, J. M. Saul, D. S. Abbott, J. J. Morse, D. Deardorff, R. J. Allain, S. W. Bonham, M. H. Dancy, and J. S. Risley, The student-centered activities for large enrollment undergraduate programs (SCALE-UP) project, Research-Based Reform Univ. Physics 1, 2 (2007), https:// www.per-central.org/items/detail.cfm?ID $=4517$.

[8] E. Brewe, V. Sawtelle, L. H. Kramer, G. E. O’Brien, I. Rodriguez, and P. Pamelá, Toward equity through participation in Modeling Instruction in introductory university physics, Phys. Rev. ST Phys. Educ. Res. 6, 010106 (2010).

[9] S. Freeman, S. L. Eddy, M. McDonough, M. K. Smith, N. Okoroafor, H. Jordt, and M. P. Wenderoth, Active learning increases student performance in science, engineering, and mathematics, Proc. Natl. Acad. Sci. U.S.A. 111, 8410 (2014).

[10] J. Michael, Where's the evidence that active learning works?, Adv. Physiology Educ. 30, 159 (2006).

[11] M. Prince, Does active learning work? A review of the research, J. Eng. Educ. 93, 223 (2004).

[12] M. Prince and R. Felder, The many faces of inductive teaching and learning, J. Coll. Sci. Teach. 36, 14 (2007), https://my.nsta.org/resource/?id=10.2505/4/jcst07_036_ $05 \_14$.

[13] T. J. Lund and M. Stains, The importance of context: an exploration of factors influencing the adoption of student-centered teaching among chemistry, biology, and physics faculty, Int. J. STEM Educ. 2, 1 (2015).

[14] M. Salomone and T. Kling, Required peer-cooperative learning improves retention of STEM majors, Int. J. STEM Educ. 4, 19 (2017).

[15] N. Sellami, S. Shaked, F. A. Laski, K. M. Eagan, and E. R. Sanders, Implementation of a learning assistant program improves student performance on higher-order assessments, CBE Life Sci. Educ. 16, ar62 (2017).

[16] V. Margoniner, J. Bürki, and M. Block, Learning-assistantsupported active-learning in a large classroom, Am. J. Phys. 88, 924 (2020). 
[17] B. Van Dusen and J. Nissen, Associations between learning assistants, passing introductory physics, and equity: A quantitative critical race theory investigation, Phys. Rev. Phys. Educ. Res. 16, 010117 (2020).

[18] A. V. Knaub, K. T. Foote, C. Henderson, M. Dancy, and R. J. Beichner, Get a room: the role of classroom space in sustained implementation of studio style instruction, Int. J. STEM Educ. 3, 1 (2016).

[19] K. Foote, A. Knaub, C. Henderson, M. Dancy, and R. J. Beichner, Enabling and challenging factors in institutional reform: The case of SCALE-UP, Phys. Rev. Phys. Educ. Res. 12, 010103 (2016).

[20] C. Keenan, Mapping student-led peer learning in the UK, Higher Educ. Acad. 8 (2014), https://www.heacademy.ac .uk/sites/default/files/resources/Peer_led_learning_Keenan_ Nov_14-final.pdf.

[21] See Supplemental Material at http://link.aps.org/ supplemental/10.1103/PhysRevPhysEducRes.17.023104 for example materials, an overview of Peer Leader tasks and instructor time commitment during a sample week, and a comparison of grading details and DFW rates in the course.
[22] CSU, Student Success Dashboard, California State University. [Data file] (California State University, Sacramento, 2020).

[23] D. Hestenes, M. Wells, and G. Swackhamer, Force Concept Inventory, Phys. Teach. 30, 141 (1992).

[24] R. R. Hake, Interactive-engagement versus traditional methods: A six-thousand-student survey of mechanics test data for introductory physics courses, Am. J. Phys. 66, 64 (1998).

[25] R. K. Thornton and D. R. Sokoloff, Assessing student learning of Newton's laws: The Force and Motion Conceptual Evaluation and the Evaluation of Active Learning Laboratory and Lecture Curricula, Am. J. Phys. 66, 338 (1998).

[26] K. O'Connor, L. A. Jung, and D. Reeves, Gearing up for FAST grading and reporting, Phi Delta Kappan 99, 67 (2018).

[27] J. Feldman, Beyond standards-based grading: Why equity must be part of grading reform, Phi Delta Kappan 100, 52 (2019). 